\title{
Active vs. passive restoration: Recovery of cloud forest structure, diversity and soil condition in abandoned pastures
}

\author{
Alma L. Trujillo Miranda ${ }^{1}$ Tarin Toledo Aceves ${ }^{1}$, Fabiola López Barrera ${ }^{1}$, Patricia Gerez Fernández² \\ ${ }^{1}$ Instituto de Ecología A. C, México. ${ }^{2}$ Universidad Veracruzana, México.
}

\section{Introduction}

Tropical montane cloud forest is a priority ecosystem for restoration due to its high diversity and the provision of ecosystem services.

We assessed the effectiveness of active (mixed plantation with native species) and passive (natural regeneration) restoration strategies implemented in pastures with 21 years of exclosure.

\section{Methods}

Study area: "Las Cañadas", Southern, Mexico.

1.Mature forest: 30 ha as a reference system.

2.Mixed plantation: 36 ha, 39,256 trees of six native species planted.

3.Passive adjacent to forest: 14 ha, livestock was excluded.

4.Passive non-adjacent to forest: 61 ha, livestock was excluded.

Indicators of vegetation structure, diversity and soil were used to evaluate the success of forest restoration strategies.

Results

\section{Forest structure}

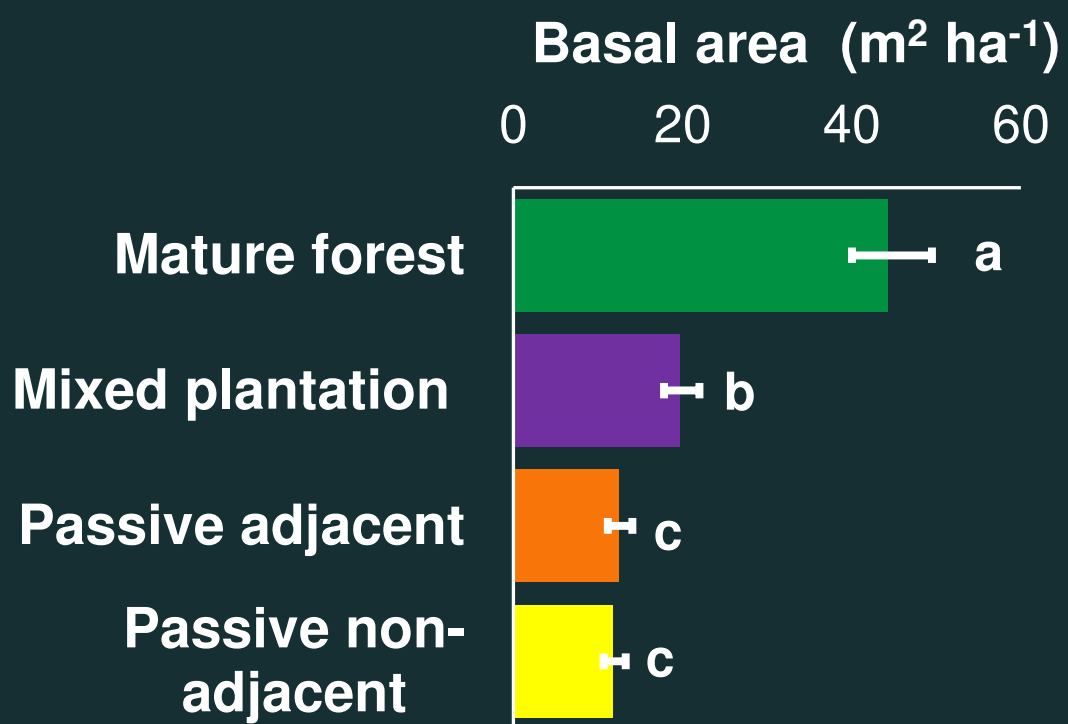

Adult tree (Individuals ha-1)
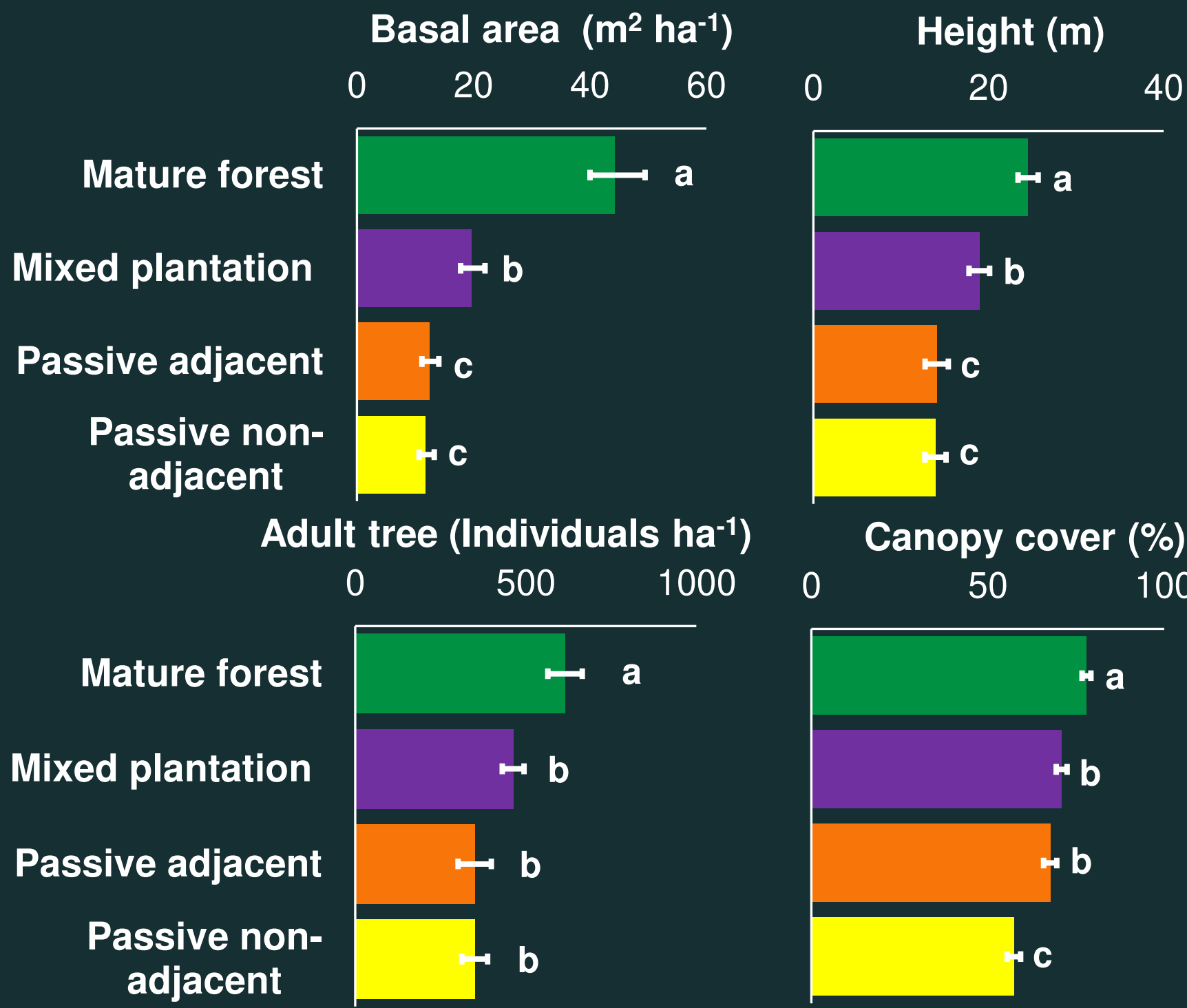

Canopy cover (\%)

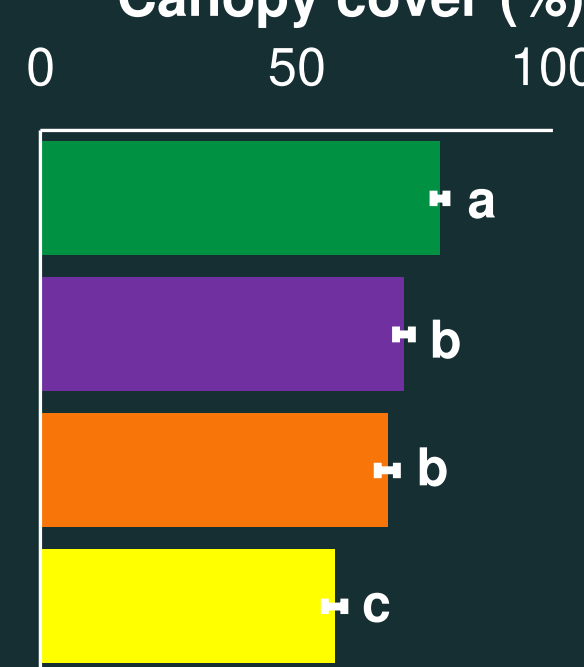

Sapling (individuals $\mathbf{~ m}^{-2}$ ) Seedling (individuals $\mathbf{~ m}^{-2}$ ) 0 0.7

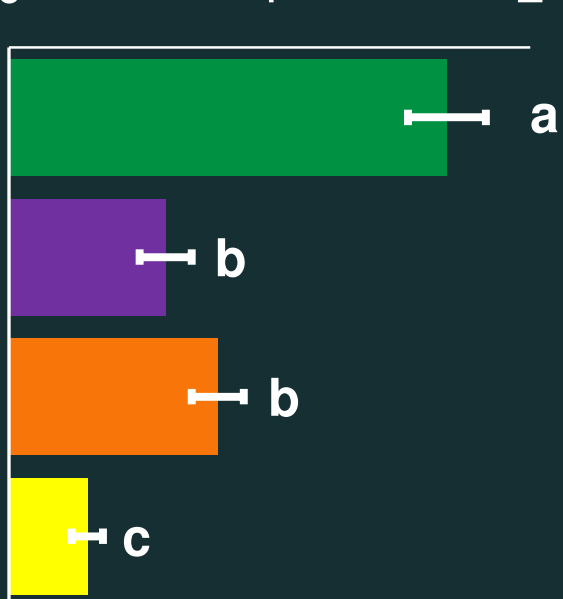

${ }^{*}$ Means that do not share a letter differ significantly among sites $(P<0.05)$.

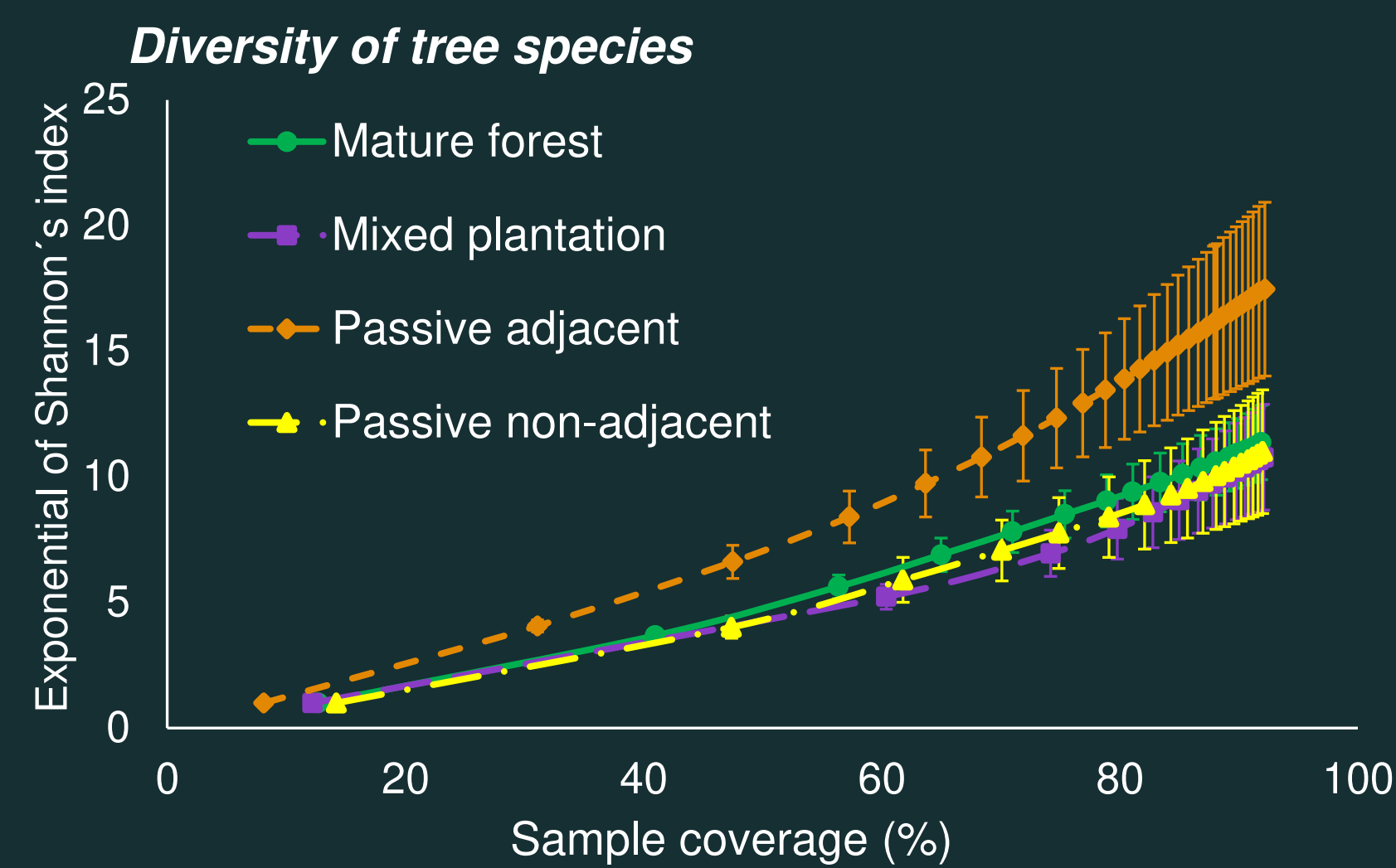

Composition of tree species

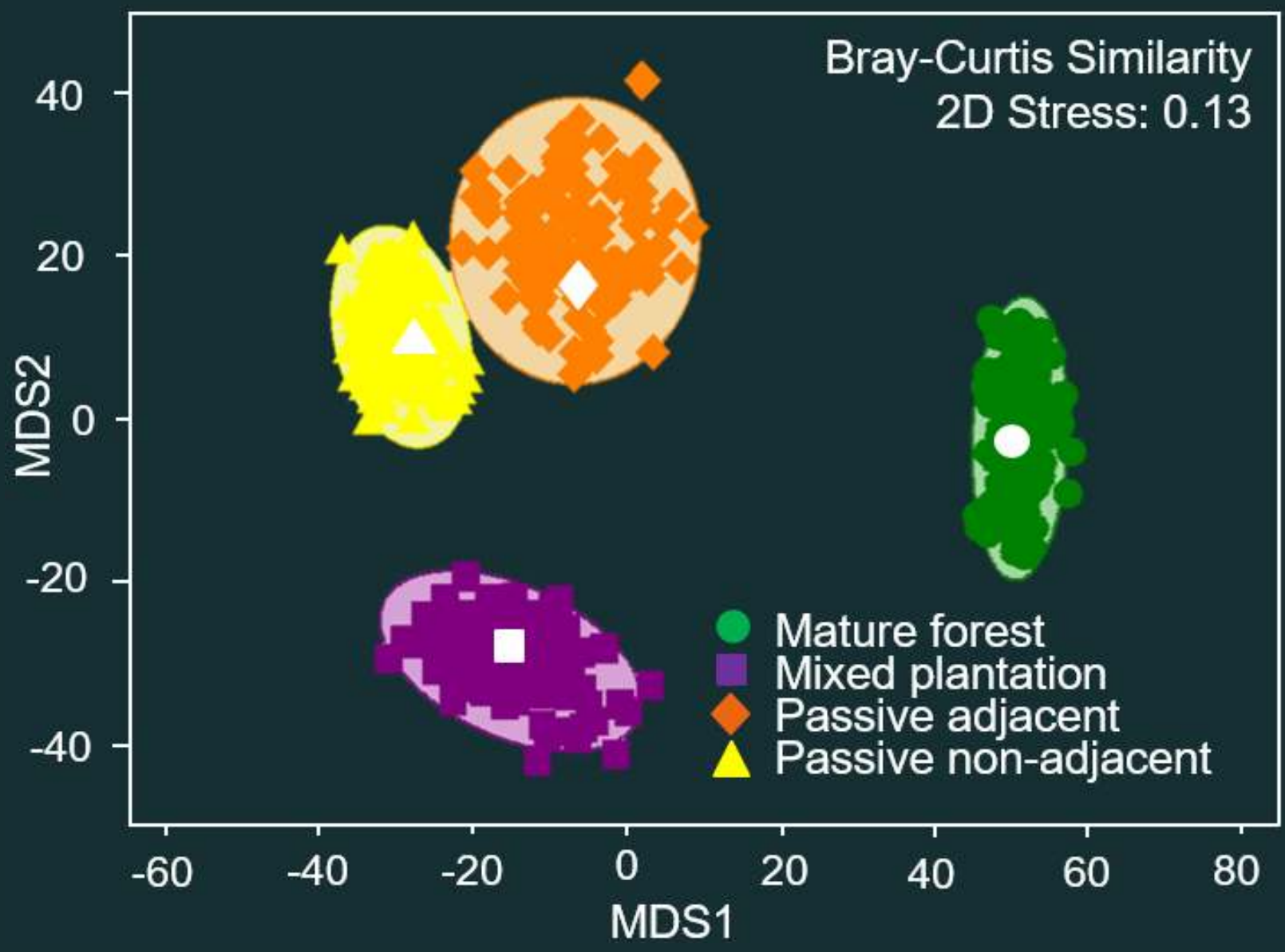

Soil properties

\begin{tabular}{|lllll|}
\hline Sites & \multicolumn{2}{c}{ Soil } & \multicolumn{2}{c|}{ Litter } \\
\hline pH & $\mathbf{C ~ ( \% )}$ & $\mathbf{C ~ ( \% )}$ & N (\%) \\
\hline Mature forest & $4.1 \mathrm{a}$ & $14.1 \mathrm{a}$ & $36.8 \mathrm{a}$ & $2.3 \mathrm{a}$ \\
\hline Mixed plantation & $5.2 \mathrm{~b}$ & $10.8 \mathrm{ab}$ & $23.7 \mathrm{~b}$ & $1.5 \mathrm{bc}$ \\
\hline Passive adjacent & $5.6 \mathrm{~b}$ & $10.4 \mathrm{ab}$ & $23.8 \mathrm{~b}$ & $1.8 \mathrm{~b}$ \\
\hline Passive non-adjacent & $5.5 \mathrm{~b}$ & $7.5 \mathrm{~b}$ & $17.8 \mathrm{~b}$ & $1.3 \mathrm{C}$ \\
\hline
\end{tabular}

\section{Conclusions}

- Active restoration was more effective than passive restoration at recovering forest structure

- Active and passive restoration adjacent to the forest matched the diversity values of the mature forest but species composition remained highly different

- The passive restoration non-adjacent to the forest had the lowest recovery, indicating the importance of proximity to seed sources

- Due to low seedling density in all of the restoration sites interventions are recommended to assist establishment of key species

- Active and passive restoration can be complementary in the restoration of cloud forest landscapes

\section{Acknowledgements}

Instituto de Ecología A. C. and CONACYT. 